\title{
Rural and Urban Differences in Household Food Insecurity and Diet Diversity of Preschool Children (PSC) in Occidental Mindoro
}

\author{
Kim Leonard G. dela Luna and Ernani R. Bullecer \\ Institute of Department of Nutrition, College of Public Health, University of the Philippines Manila
}

\begin{abstract}
Objective. Rural and urban differences affect food availability, accessibility, and sustainability; thus, it has a great impact on household food security and dietary diversity. The relationship between the human environment and other factors threatens different domains of food systems resulting in food security. The objective of this study is to determine significant differences between the prevalence of household food security and diet diversity between urban and rural communities in Occidental Mindoro. Specifically, to determine the pattern of usual food intake of preschool children between rural and urban communities
\end{abstract}

Methods. This study utilized a comparative, cross-sectional, analytic study design in order to determine the prevalence of each variable of interest in the two study areas. Radimer-Cornell Tool was utilized to assess the food security status of the household while the FAO-Dietary Diversity Score Questionnaire was used to the diversity of diet among PSC. A total of 480 (rural: $n=240$; urban: $n=240$ ) preschool children were recruited to participate in this study. Ratio and proportion using the point and interval estimate were used to determine the prevalence in different areas, meanwhile, chi-square of homogeneity was used to determine significant difference in the two areas under study.

Results. Food insecurity in rural communities was found to be at $56.25 \%$ (95\% Cl: $49.97 \%$ to $62.53 \%$ ) while the prevalence in urban communities was $45.83 \%$ (95\% Cl: $39.53 \%$ to $52.14 \%)$. There was a significant difference in the prevalence of household food insecurity between rural and urban communities $(p=0.0224)$. Meanwhile, the prevalence of less dietary diversity among preschool children in rural communities was 37.08\% (95\%: $30.97 \%$ to $43.19 \%)$ and $26.25 \%(\mathrm{Cl}: 20.68 \%$ to $31.82 \%)$ for urban communities. There was a significant difference in prevalence of low dietary diversity score among preschool children between rural and urban communities $(p=0.0107)$.

Conclusion. There were significant differences in terms of household food insecurity and less diverse diet between two community settings. Higher prevalence in rural areas signifies that there is a need to prioritize these vulnerable communities in terms of hunger mitigation and nutrition programs. A combination of milk-rice-meat-fish was observed in the diet of preschool children for both communities however, higher prevalence of less dietary diversity was detected among rural communities.

Key Words: household food insecurity, dietary diversity score, preschool children

\section{INTRODUCTION}

Paper presented at the $7^{\text {th }}$ Seoul International Congress of Endocrinology and Metabolism, April 18-21, 2019, Sheraton Hotel, Grande Walker Hill, Seoul, Korea.

Corresponding author: Kim Leonard G. dela Luna, RND, MSPH Department of Nutrition

College of Public Health

University of the Philippines Manila

625 Pedro Gil St., Ermita, Manila 1000, Philippines

Email: kgdelaluna@up.edu.ph; kimleonard_21@yahoo.com
Food insecurity affects over 800 million people, with the majority coming from the developing countries. ${ }^{1}$ It could result in different problematic issues concerning mothers and children more specifically because of vulnerability to develop undernutrition and psychosocial problems. ${ }^{2}$ Research findings suggest that household with moderate to severe food insecurity has lower dietary diversity scores compared to food secure households. ${ }^{3}$ 
Food insecurity is a multi-dimensional concept which exists when the population at all times has the access to sufficient, safe and nutritious foods that allow them to meet their dietary needs for a healthy and active life. ${ }^{4}$ Figure 1 summarizes the different dimensions resulting to food security which includes food availability, food access, food utilization and stability of these three dimensions. The model of food security goes beyond caloric intake which addresses both hunger and undernutrition. ${ }^{5}$

Household food security is a multi-dimensional concept which can be collectively explained by different factors. One of the biggest variables that affect household food insecurity and also influences dietary diversity is the agroecological differences between rural and urban communities. ${ }^{6}$ Research findings reveal that women and families in rural areas are susceptible to household food insecurity and its consequences. This is due to less education, lower wages, and fewer long-term employment opportunities. ${ }^{7}$

Urbanization and globalization are causing rapid changes to food supply over time. ${ }^{8}$ Different factors also affect the food system and food distribution while climate change directly influences crop production of rural farmers due to changes in rainfall leading to drought or flooding. This may lead to decreased harvest among farmers in rural areas resulting in price inflation among urban communities.

Urban-rural differences affect food availability, accessibility and sustainability; thus, it has a great impact on household food security and dietary diversity. This factor can be explained by the ecology of the food system known as agroecology. ${ }^{9}$ Agroecology has a definite goal in gearing food systems towards sustainability by which there will be an equilibrium between soundness, social justice, and economic viability. ${ }^{10}$ The forceful relationship between the human environment and biogeophysical factors affects the different domains of food systems resulting in food security. ${ }^{11}$
In the country, the Philippines Standard Geographical Code (PSGC) determines the classification of communities into rural and urban barangays. ${ }^{12}$ This is mainly based on characteristic of the environment, availability of primary services, facilities and establishments within a specific barangay.

The National Nutrition Survey in the Philippines revealed that more than a quarter of Filipino adults or thirtysix percent (36\%) and twenty-three percent $(23 \%)$ of children claimed to be food insecure, respectively. The magnitude of the problem is persistently scattered across the sixteen (16) regions of the country. ${ }^{13}$ Based on the result of the SWS, two million (2) Filipino families experienced moderate food hunger and six hundred twenty-one thousand $(621,000)$ Filipino families suffered from severe hunger. ${ }^{14}$

Based on the result of the $8^{\text {th }}$ National Nutrition Survey, preschool children (6 months - 5 years) had 843 kcal daily mean per capita intake in terms of energy and $26.1 \mathrm{~g}$ of protein per day. Qualitatively, these research findings showed that there is a pattern of milk-rice-meat-fish combination complemented with a little portion of fruits was observed in the usual diet of preschool children. This survey result also showed that more than $75 \%$ of the Filipinos across the population groups lacks energy from their daily intake. ${ }^{11}$ In a separate study, it was found out that almost one-third of the food intake of preschool children was contributed by milk and milk products followed by cereals and cereal products and fish and fish products. ${ }^{15}$

Different strategies have been implemented to alleviate the effect of hunger and food insecurity globally. The National Nutrition Council (NNC) is the implementing lead agency of Philippine Plan of Action (PPAN) 20172022 which is anchored in Ambisyon 2040 that aims to provide a comfortable and secured life for every Filipinos. One of the underlying causes of undernutrition among

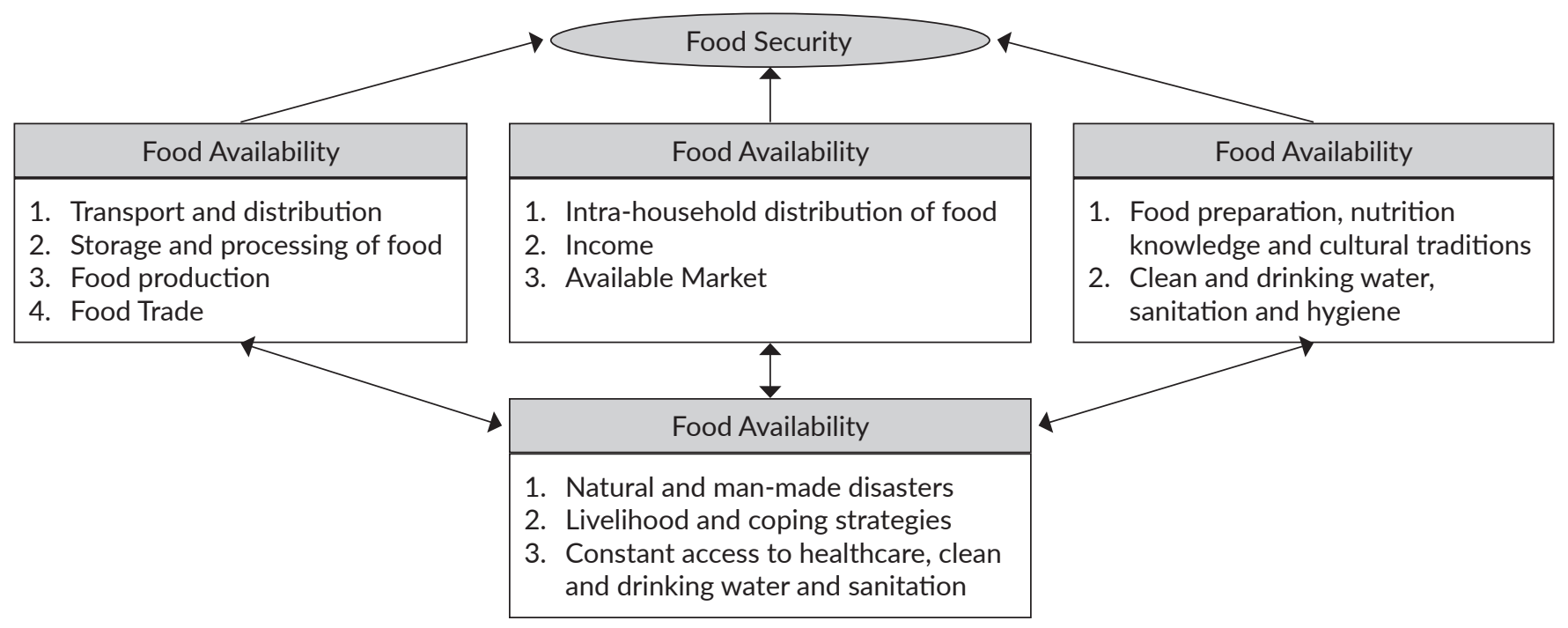

Figure 1. Multi-dimensional concept of food security as adapted from the Food and Agriculture Office Model (2010). 
children was household food insecurity. Government agencies are targeting these root causes of undernutrition through the provision of nutrition-sensitive programs as one of PPAN 2017-2022 Strategic Thrusts. Nutritionsensitive programs are non-nutrition programs that were tweaked to produce positive nutritional outcomes such as increasing available foods for the community, improving infrastructure, providing sustainable and accessible foods. ${ }^{16}$

The magnitude of household food insecurity and less diversity of diet in the country is well-observed in different research findings. However, limited studies further determine the difference between the problem between different communities. The gap in this literature demands that there is a need to conduct a methodological study that can identify the magnitude difference between communities which can help local leaders to identify areas needed more priority in terms of food security and nutrition programs.

The major objective of this study is to determine significant differences between the prevalence of household food security and diet diversity between urban and rural communities in Occidental Mindoro. Specifically, this study aims to identify the usual food intake of preschool children according to Dietary Diversity Score among rural and urban communities in the province.

\section{MATERIALS AND METHODS}

\section{Study Design}

In order to answer the objectives, the comparativecross sectional, analytic study design was used. This design allowed to measure the prevalence of all variables and enable to compare one from another at one point while maximizing the resources. The stratification of communities followed the rules set by the PSGC as urban and rural communities.

Based on this classification, in order to be classified as an urban barangay the following classification must be met: population density must be at least 1,000 persons per square kilometer if within municipal jurisdictions and 500 persons square kilometer if within central districts; there must be a street pattern or network streets and at least six establishments (commercial, manufacturing, recreational and/ or personal services); barangay must have at least three of the following (town hall, church or chapel, market place, public plaza, building with trading activities and public building that include school, hospital, puericulture and health center); and barangay must have at least 1000 inhabitants. Meanwhile, other barangays which didn't meet these criteria were considered as rural barangays.

\section{Sampling Design}

Three multi-stage stratified simple random sampling was used to determine the sample of this study. At the start of sampling design, the names of municipalities were listed and randomly selected through simple random sampling. Three (3) municipalities had been drawn from the list. After the three municipalities were identified, barangays in each respective municipalities were stratified according to rural and urban communities based on the Philippines Standard Geographical Code (PSGC).

Equal allocation of barangay was observed to meet the sample size requirement. Eleven (11) barangays were allocated in each classification. After the three municipalities were identified, barangays were listed according to strata: rural and urban communities. From each strata, 11 barangays were drawn from each frame.

After the barangays had been identified in each strata, 21 households with at least one preschool children studying in Barangay Day Care Center were chosen using the set inclusion and exclusion criteria through systematic random sampling in order to meet the minimum sample size requirement.

Households were selected using the inclusion criteria: a household with at least one preschool child studying in the Barangay Day Care Center. However, children diagnosed with congenital physical and mental disability and mothers or preschool children who were not able to complete the evaluation were also excluded. Moreover, mothers or caregivers who weren't able to finish the data collection process because of any reason were automatically withdrawn in the conduct of the study. Lastly, children who were sick during the data collection process were also excluded from the conduct of the study. In total, 240 preschool children participated in each stratum.

\section{Data Collection Procedure}

This study utilized different tools to gather data: (1) Radimer-Cornell Tool which was being used to determine the food security status of a household and (2) Dietary Diversity Score Questionnaire to assess the dietary diversity score of the preschool children under study.

\section{Radimer-Cornell Tool}

Radimer-Cornell Tool can measure hunger and food insecurity which was developed from the experiences of hunger and food insecurity. ${ }^{17}$ It has been used in different countries particularly in developing and developed countries to evaluate the food security status of the household. ${ }^{18,19,20}$ In the Philippines, the use of Radimer-Cornell Tool serves as a valid indicator of household food insecurity even it produces a higher proportion of total variance when used at the individual level. This issue did not impede the ability of the tool to detect household food insecurity. ${ }^{21}$ This tool was administered among the mothers of preschool children wherein statements were read and allow participants to decide whether they had experienced the written statements or not. If the mother gave an affirmation in at least one written statement for the last three months, it classified the household as food insecure. 


\section{Individual Dietary Diversity Score}

In order to assess the dietary diversity of preschool children, this study used the FAO Individual Dietary Diversity Score Questionnaire. These scores intend to reflect nutrient adequacy since other research findings suggested that an increase in individual dietary diversity scores also reflected nutrient adequacy. ${ }^{22,23}$ The constructed questionnaire was purely based on the set guidelines of the Food Agriculture Office (FAO) for dietary diversity score questionnaires. ${ }^{24}$ A 24-hour food recall was administered among mothers regarding the food intake of their children for the past 24 hours. This food recall served as a reference for the Individual Dietary Diversity Score Questionnaire which summarized the food intake of the child.

FAO used a reference period of past 24-hours, using a 24-hour food recall period can't provide an indication of an individual's usual dietary intake but it does provide an evaluation of the usual dietary intake at population level. ${ }^{25}$ The use of a 24-hour recall period was used by the FAO because it is subjected to recall bias, minimal burden for the participants of a study and follows the recall time period used in many dietary diversity studies..$^{24,26,27}$

Nine (9) point individual dietary diversity score was used to determine the diversity of the diet of preschool children. In order to classify, the dietary intake as a more diverse diet, the study used the $\geq 5$ food group as a cut-off point. This cut-off point was based on the study conducted in the Philippines which determine that 5 out of 9 food groups already reflects the adequacy of nutrients. This determined cut-off point is defined as the less risk micronutrient inadequacy and a more diverse diet. ${ }^{28}$

Before data collection started, informed consent was administered among mothers and caregivers of preschool children. The consent explains the rights of the respondents as well as the confidentiality of information after data collection. Conduct of this research was approved by the University of the Philippines-Manila Review Ethics Board with the approval code UPMREB 2016-315-01. Data collectors were registered nutritionist-dietitians who were trained to use the Radimer-Cornell Tool and Dietary Diversity Score Questionnaire through technical assistance provided by the Food and Nutrition Research Institute and Provincial Social Welfare and Development Office of Occidental Mindoro.

\section{Data Analysis}

Ratio and proportion using the point and interval estimate were used to determine the prevalence of household food insecurity and less dietary diversity among preschool children. Meanwhile, in order to determine the difference between the prevalence of food insecurity and less dietary diversity among preschool children between rural and urban communities, the chi-square of homogeneity was utilized. An $\alpha=.05$ was used to determine if there was a significant difference between the prevalence in the two settings when compared.

\section{RESULTS}

\section{Description of Participants when stratified into Rural and Urban Communities}

Table 1 presents the characteristic of the participating household and preschool children. The mean age of preschool children from a rural area (53.07 \pm 8.52 months) was slightly higher compared to an urban area (52.09 \pm 7.75 months). In terms of the household size, both urban and rural community have almost the same number of family members sharing in the same pot. The greatest proportion of households from both urban (67\%) and rural (70\%) communities had a monthly income of <PHP. 6, 000.00.

Almost half (45\%) of the fathers from rural communities were farmers while highest proportions of the fathers (26\%) from urban communities were skilled workers (e.g., welder, driver, technician, and other related jobs). However, unemployment for both rural and urban communities was recorded at $10 \%$.

Meanwhile, in terms of the occupation of mothers for both rural and urban community, the highest percentage of the mothers were housewives ( $76 \%$ and $75 \%$, respectively). The remaining percentages mostly engage in non-permanent work and jobs such as housemaids, contractual employees of some private companies and vendor.

Lastly, in terms of the government support given such as the Conditional Cash Transfer (CCT) and Mangyan/ Minority Conditional Cash Transfer (MCCT), the rural households had higher (35\%) coverage compared to urban communities with only $22 \%$ of coverage.

\section{Prevalence Difference in terms of Household Food Insecurity between Rural and Urban Communities}

Table 2 summarizes the prevalence of household food insecurity between rural and urban communities. Prevalence of food insecurity in rural communities was found to be at $56.25 \%$ (95\%CI: $49.97 \%$ to $62.53 \%$ ) while the prevalence of food insecurity in urban communities was $45.83 \%$ (95\% CI: $39.53 \%$ to $52.14 \%)$. There was a significant difference in the prevalence of household food insecurity between rural and urban communities in Occidental Mindoro ( $\mathrm{p}=0.0224)$. Furthermore, the prevalence in rural communities was significantly higher than in urban communities $(\mathrm{p}=0.0112)$.

\section{Prevalence Difference in terms of Dietary Diversity among Preschool Children between Rural and Urban Communities}

Table 2 also shows the prevalence of less dietary diversity among preschool children in both communities. Result of DDS showed that prevalence of less dietary diversity among preschool children in rural communities was $37.08 \%$ (95\%: $30.97 \%$ to $43.19 \%$ ) while the prevalence in urban communities was $26.25 \%$ (CI: $20.68 \%$ to $31.82 \%$ ). There was a significant difference in the prevalence of low dietary diversity score among preschool children between 
Rural and Urban Differences in Household Food Insecurity and Diet Diversity

Table 1. Characteristic of participating household and preschool children in Occidental Mindoro, 2016 ( $n=480)$

\begin{tabular}{|c|c|c|c|c|}
\hline \multirow[b]{2}{*}{ Characteristics } & \multicolumn{2}{|c|}{ Rural Communities } & \multicolumn{2}{|c|}{ Urban Communities } \\
\hline & $\begin{array}{c}\text { No. } \\
n=240\end{array}$ & $\begin{array}{c}\text { Percent } \\
\text { (\%) }\end{array}$ & $\begin{array}{c}\text { No. } \\
n=240\end{array}$ & $\begin{array}{c}\text { Percent } \\
\text { (\%) }\end{array}$ \\
\hline \multicolumn{5}{|l|}{ Demography } \\
\hline \multicolumn{5}{|l|}{ Sex } \\
\hline Male & 107 & 45 & 118 & 49 \\
\hline Female & 133 & 55 & 122 & 51 \\
\hline Mean Age (in months) & \multicolumn{2}{|c|}{$53.07 \pm 8.52$} & \multicolumn{2}{|c|}{$52.09 \pm 7.75$} \\
\hline Household Size & \multicolumn{2}{|c|}{$4.86 \pm 1.35$} & \multicolumn{2}{|c|}{$4.8 \pm 1.34$} \\
\hline \multicolumn{5}{|l|}{ Socio-economic } \\
\hline \multicolumn{5}{|l|}{ Household Income } \\
\hline <PHP. 6000.00 & 169 & 70 & 160 & 67 \\
\hline PHP. 6,001.00 - PHP. $15,000.00$ & 48 & 20 & 60 & 25 \\
\hline PHP. 15, 001.00 - PHP. 25,000.00 & 19 & 8 & 16 & 7 \\
\hline >PHP. $25,001.00$ & 4 & 2 & 4 & 2 \\
\hline \multicolumn{5}{|l|}{ Occupation of Father } \\
\hline Skilled Worker & 56 & 23 & 63 & 26 \\
\hline Employee- Private companies & 10 & 4 & 28 & 12 \\
\hline Farmer & 107 & 45 & 40 & 17 \\
\hline Fisherman & 32 & 13 & 61 & 25 \\
\hline Government Employee & 6 & 3 & 16 & 7 \\
\hline OFW & 6 & 3 & 8 & 3 \\
\hline Unemployed & 23 & 10 & 24 & 10 \\
\hline \multicolumn{5}{|l|}{ Occupation of Mother } \\
\hline Employee- Private companies & 25 & 10 & 26 & 11 \\
\hline Government Employee & 8 & 3 & 8 & 3 \\
\hline Housemaid & 9 & 4 & 7 & 3 \\
\hline OFW & 9 & 4 & 7 & 3 \\
\hline Farmer & 1 & 1 & 4 & 2 \\
\hline Vendor & 5 & 2 & 7 & 3 \\
\hline Housewife & 183 & 76 & 181 & 75 \\
\hline \multicolumn{5}{|l|}{ Recipient of Government Support } \\
\hline Yes & 85 & 35 & 53 & 22 \\
\hline No & 155 & 65 & 187 & 78 \\
\hline
\end{tabular}

Table 2. Difference in the prevalence of food insecurity and less dietary diversity among preschool children between urban and rural communities in Occidental Mindoro, 2016

\begin{tabular}{|c|c|c|c|c|}
\hline & $\begin{array}{c}\begin{array}{c}\text { Rural } \\
n=240 n\end{array} \\
(\%)\end{array}$ & $\begin{array}{c}\text { Urban } \\
n=240 \\
n(\%)\end{array}$ & $\begin{array}{c}\text { Total } \\
\mathrm{n}=480 \\
\mathrm{n}(\%)\end{array}$ & p-value \\
\hline $\begin{array}{l}\text { Dietary Diversity } \\
\text { Low } \\
\text { More }\end{array}$ & $\begin{array}{r}89(37) \\
151(63) \\
\end{array}$ & $\begin{array}{r}63(26) \\
177(74)\end{array}$ & $\begin{array}{l}152(32) \\
328(68)\end{array}$ & 0.0107 \\
\hline $\begin{array}{l}\text { Food Security } \\
\text { Insecure } \\
\text { Secure }\end{array}$ & $\begin{array}{l}135(56) \\
105(44)\end{array}$ & $\begin{array}{l}110(46) \\
130(54)\end{array}$ & $\begin{array}{l}245(51) \\
235(49) \\
\end{array}$ & 0.0224 \\
\hline
\end{tabular}

rural and urban communities $(\mathrm{p}=0.0107)$. Furthermore, the prevalence in rural communities was significantly higher than in urban $(\mathrm{p}=0.0054)$.

Source of Diversity in the Dietary Intake of Preschool Children between Urban and Rural Communities

Table 3 presents the proportion of preschool children consumption based on each food group categories as listed in the Dietary Diversity Questionnaire. In both communities, all (100\%) of the preschool children consumed the cereals,
Table 3. Proportion of children consuming specific food groups based on DDS in Occidental Mindoro, 2016

\begin{tabular}{|c|c|c|c|}
\hline Food Groups & $\begin{array}{c}\text { Rural } \\
\mathrm{n}=240 \\
(\%)\end{array}$ & $\begin{array}{c}\text { Urban } \\
\mathrm{n}=240 \\
(\%)\end{array}$ & p-value \\
\hline Cereals, tubers, grains and products & 100 & 100 & 1.00 \\
\hline $\begin{array}{l}\text { Flesh meats, seafood, internal organ } \\
\text { and its product }\end{array}$ & 89 & 90 & 0.66 \\
\hline Oils and Fats & 82 & 86 & 0.26 \\
\hline Vitamin A rich fruits and vegetables & 59 & 65 & 0.16 \\
\hline Other vegetables & 49 & 48 & 0.85 \\
\hline Dairy products & 44 & 49 & 0.27 \\
\hline Eggs & 42 & 48 & 0.14 \\
\hline Legumes, pulses and nuts & 19 & 20 & 0.73 \\
\hline Other fruits & 7 & 9 & 0.40 \\
\hline
\end{tabular}

tubers, grains and its product $(\mathrm{p}=1.00)$. Another significant part of the dietary diversity in both urban and rural communities ( $90 \%$ and $89 \%$, respectively) were the sources of protein which includes flesh meats, seafood, internal organ, and its product.

Meanwhile greater portion of the respondents for both communities were consuming fats and oils. A higher proportion (86\%) from urban communities consumed this 
food group compared to $82 \%$ of the rural communities $(p=0.26)$. In terms of the vegetable consumption primarily those included in the vitamin A-rich products, there are more (65\%) preschool children from urban communities included this food group in their diet compared to $59 \%$ from rural communities $(\mathrm{p}=0.16)$.

Among the food groups with lower rates of consumption for both communities were eggs, legumes, pulses and nuts and fruits which were not considered as vitamin A-rich one. For both communities, lower ( $9 \%$ for urban communities; $7 \%$ for rural communities) consumption was recorded in this food group ( $\mathrm{p}=0.40)$.

Qualitatively the food patterns for both community was the same which a combination of rice, fish or meat cooked with oil and fat with a small serving of vitamin A- rich fruits and vegetables. In both communities, preschool children were less likely to consume dairy products and eggs.

\section{DISCUSSION}

\section{Description of Participants when stratified into Rural and Urban Communities}

Agriculture is an important employment source for rural people because it requires a high demand for lowskill labor intensive jobs. ${ }^{29}$ In this study, majority of the fathers from rural communities were farmers. This is in relation to the record that almost $80 \%$ of the population including children were involved in farming and agriculturerelated work. ${ }^{30}$

Meanwhile, most of the fathers from urban communities were skilled workers which include, but are not limited to welders, drivers, technicians and other related jobs. This can be explained by the changes in the working pattern in the province that can explain the difference in terms of employment between two communities. Shift in employment within the food system when the gradient of urbanization was included, fewer people work in the agriculture sector and more are working in transport, wholesale, retailing, food processing, and vending. ${ }^{31}$ The United Nations projections suggest that the world's urban population will rapidly increase compared to the rural population. ${ }^{32}$

The recorded unemployment rate in the Philippines (5.8\%) was lower compared to the estimate produced by this study for unemployment for both rural and urban communities which was recorded at $10 \% .{ }^{33}$ Governments in developing countries have long struggled to conquer food insecurity and malnutrition through the implementation of hunger mitigation programs, conditional cash transfer, work for cash and other related programs that targeted the vulnerable group in a community.

Based on the findings of this study, there was a higher number of household proportion from the rural household which is a recipient of government support intended for hunger mitigation program in the province. This higher proportion of household food insecurity in rural areas can explain the higher coverage of conditional cash transfer and other related programs.

In terms of household size in this study, the number of family members sharing in one pot was almost the same in rural and urban areas. In the Philippines, the average household size was 4.4 lower compared to the result of this study. ${ }^{34}$ However, there were no results that disaggregate the household size in the country into rural and urban classification.

Educational levels of adults in a household with preschoolers are much lower in rural than in urban areas, reflecting the levels in the general population. Moreover, urban household have greater access to enhanced sanitation and piped water or public taps. ${ }^{6}$

\section{Prevalence Difference in terms of Household Food Insecurity between Rural and Urban Communities}

Results of this study showed that the prevalence of household food insecurity was significantly different between the two community classifications. Higher food insecurity levels were found among rural communities compared to urban communities. The result of this study can be supported by other studies suggesting that other determinants of food and nutrition security were better in urban compared to rural communities.

In the study conducted in the United Kingdom, levels of food insecurity were lower in urban areas compared with rural and peri-urban areas with the peri-urban households being the most affected. In Dundee alone, about $27 \%$ of the households were severely food insecure in peri-urban zone. ${ }^{35}$ Meanwhile relating this result to dietary diversity, it was noted that the fewer food groups a household consumed, the higher the level of food insecurity. The most affected were the peri-urban and rural household. ${ }^{36}$

Urban dwellers had access to purchase available food compared to those who settled in rural communities. Rural dwellers tend to rely on their owned gardens and supplies came from social assistance programs or in other households. ${ }^{6}$ It was also suggested that food insecurity was slightly higher in urban areas than in the countryside. Sixtyseven percent of the urban population was food insecure, compared to $64 \%$ of rural residents. These aggregates can mask other important regional differences.

Different research findings may indicate agro-ecological conditions between countries vary depending on the criteria set by the local government or standards set by different researchers. This undertaking follows the criteria set by the Philippine Standard Geographic Code (PSGC) in delineating rural from urban communities.

\section{Prevalence Difference in terms of Dietary Diversity among Preschool Children between Rural and Urban Communities}

Expenditure elasticity for calorie availability was slightly higher in urban than in rural areas (0.14 compared 
to 0.12 ), which suggests that urban-dweller was more likely to spend and increase in income on food than a ruraldweller. ${ }^{6}$ In this study, it was found out that the prevalence of low dietary diversity score between rural communities and urban communities was significantly different $(\mathrm{p}=0.0107)$. Prevalence in rural was significantly higher than in urban communities.

In relation to another study, after controlling for income, urban residents on average consume more diverse diets than the rural environment. This implies that some force other than income is driving this pattern. The findings of the present study suggested that the regional differences in dietary diversity can be a cause of higher cost of access, driven by lower availability, higher transaction costs of seeking and obtaining variety, and limited access to improved food storage and added marginal costs. ${ }^{37}$

In relation to food security to dietary diversity, nutrient intakes were the highest among children from the household food insecure group, followed by those from the food secure, adult food insecure and child hunger households. ${ }^{38}$ In this study, the relationship between household food insecurity was not explored because of inadequate sample size requirement.

In order to elaborate on the variation in dietary diversity of preschool children between the two communities, a clear association between socio-economic status (SES) and dietary diversity among urban and rural communities can be observed. In some correlational studies, it was found that among urban communities there was 0.3 correlation between SES and dietary diversity. The level of dietary diversity in rural communities tends to be lowered compared to urban communities. The variances in DDS between high and low SES groups were mainly due to differences in some of the food groups. ${ }^{23}$

Being an agricultural province, the result of the study posed important findings. The underutilization of available resources such as farmable areas and possible sources could lead to a high prevalence of less diverse food intake among preschool children in the province. Second, the active participation of mothers and caregivers in existing government programs which focused on appropriate complementary feeding and child-rearing practices. Even though not explored by the study, the possibility of inactive participation of mothers in government programs like poor utilization of vegetable gardens in the barangay and lack of knowledge in food preparation resulted to different problematic issues affecting food intake of preschool children.

Moreover, research findings show that agricultural policies had been focused on the improvement of crop yields and never designed to promote human health and just mainly focused on the increased profitability of agricultural industries. ${ }^{39}$ Among developing countries in Asia, the "Green Revolution" was launched during the 1970s when farming technologies, pesticides and fertilizers had been introduced to increase agricultural productivity but it did not target hunger alleviation. ${ }^{40}$ Before this period, a big proportion of the agriculture sector in Asia maintained a more diversified agricultural production system which includes the propagation of legumes and pulses but due to the introduction of new techniques a few staple crops can contribute to more simplified diets which can also equate to unresolved issues of undernutrition in South Asia and widespread micronutrient deficiency. ${ }^{41}$

\section{Source of Diversity in the Dietary Intake of Preschool Children between Urban and Rural Communities}

Findings of this study suggested that most of the preschool children in urban communities consumed cereals, tubers, grains and products (100\%), meats, seafood, internal organs (90\%), oils and fats (85.83\%) and vitamin A rich fruits and vegetables (65.42\%). Therefore, the typical meal consumed by preschool children in urban communities in Occidental Mindoro was composed of rice, fish or meat which was usually served fried with green leafy vegetables.

In addition, all (100\%) of preschool children in rural communities consumed cereals, tubers, grains, and products. Another group of foods which were usually part of preschool children in rural communities includes the following: meats, seafood, internal organs (88.75\%), oils and fats (82.08\%) and Vitamin A rich fruits and vegetables (59.17\%). The typical diet of preschool children in rural communities in Occidental Mindoro was almost similar to urban dwellers. However, a lower consumption rate for other food groups was found among preschool children in urban communities. This result was also observed on the $8^{\text {th }}$ National Nutrition Survey which concluded that the typical meal of a Filipino was composed of rice, fish, and vegetable. ${ }^{13}$

Moreover, this can be supported by the results of this study which suggested that there was lower intake of legumes, pulses, and nuts as well as other fruits (not considered as Vitamin A rich fruits) in both urban and rural communities. This was an alarming finding since these foods can be possibly planted in the available farmable area in the community which can be targeted by government programs through community gardening.

In another study, it is found out that the diet of the Filipino children were based on different combinations of rice, meat or fish, oils, vegetables, and fruits. Filipino children had a mean DDS of nearly five (4.9) out of the nine (9) food groups. Iron, calcium, and zinc tend to be the nutrients with the lowest adequacy ratios. ${ }^{28}$ Based from this study, similar to the study conducted in Kenya the best cutoff point to use to maximize the sensitivity and specificity was a diversity score of 5 which utilized the $50^{\text {th }}$ percentile of Mean Probability of Adequate Intake (MPA). ${ }^{42}$

\section{Limitation of the study}

The variation in the result of this study from different related studies can be attributed to the difference in sampling 
design used and the type of tool used during the data collection procedure. Generalizability of data was limited to the mainland municipalities as well as to household with preschool children enrolled in center-based day care centers. Moreover, the prevalence of both household food insecurity and less dietary diversity in the study areas produces a wide confidence interval that can be explained by small sample size. The precision of the estimates was purely based on the number of respondents under study.

The findings can be also affected by recall bias due to the use of the 24-hour food recall and Radimer-Cornell Tool to determine the outcomes of this study. Each tool purely relies on the memory of the mothers or caregivers since it is a recall of past events. The Radimer-Cornell Tool relies on the experiences of the mothers or caregivers for the past three months while the Dietary Diversity Score was purely based on the past 24-hour food consumption of preschool children. Lastly, the responses of the mothers might be based on their perceptions on how they will be adjudicated from the survey which can be further explained by social desirability and acceptability bias.

\section{CONCLUSION}

In spite of the fact that the prevalence of household of food insecurity and less diverse diet in Occidental Mindoro was lower compared to the national estimates, it remained of high public health significance. Result of this study indicated that the difference in the prevalence of household food insecurity and less diverse diet in urban and rural communities were statistically significant. Moreover, the prevalence of household food insecurity and less diverse diet were both higher in rural communities.

Moreover, the biggest proportion of children from both communities relies on the rice-fish-vegetable combination. The usual food items consumed by preschool children for both communities include cereals, tubers, grains, and its product; flesh meat, seafood, internal organ, and its product; oils and fats; and Vitamin A rich fruits and vegetables. However, lowest food consumption were recorded in eggs and its products; legumes, pulses and nuts; and other fruits not classified as Vitamin A rich fruits but rich in other micronutrients.

These findings suggested that rural dwellers need more assistance to improve their food security status as well as assistance in improving the adequacy of diet through different interventions. The higher level of prevalence of food insecurity and less diverse diet in rural communities must be taken into considerations because children in rural communities were closely to experience food security and low dietary diversity score thus needs better access for government services. Strategies on food and nutrition security must be focused in rural communities that will allow better promotion and utilization of a variety locally available foods. ${ }^{43}$ This should be the focus of future hunger mitigation and nutrition programs because unresolved issues of household food insecurity and less diverse diet among preschool children preclude many problematic issues in terms of nutritional and health status together with other psychosocial problems.

\section{Statement of Authorship}

Both authors participated in data collection and analysis, and approved the final version submitted.

\section{Author Disclosure}

Both authors declared no conflicts of interest.

\section{Funding Source}

This study was funded by the Department of Science and Technology-Science Education Institute (DOST-SEI) and implemented under the Department of Nutrition, College of Public Health, University of the Philippines Manila.

\section{REFERENCES}

1. Food and Agriculture Organization of the United Nations. The state of food insecurity in the world 2004: monitoring progress towards the world food summit and millennium development goals. Rome: FAO; 2004.

2. Ke J, Ford-Jones EL. Food insecurity and hunger: A review of the effects on children's health and behaviour. Paediatr Child Health. 2015 Mar; 20(2):89-91.

3. Chandrasekhar S, Aguayo VM, Krishna V, Nair R. Household food insecurity and children's dietary diversity and nutrition in India. Evidence from the comprehensive nutrition survey in Maharashtra. Matern Child Nutr. 2017 Oct; 13(S2):e12447. doi:10.1111/mcn.12447.

4. Rome Declaration on World Food Security and World Food Summit Plan of Action [Internet]. FAO: Rome, Italy, 1996 [cited 2019 Mar 23]. Available from: http://www.fao.org/docrep/003/w3613e/ w3613e00.htm.

5. Pelletier DL, Frongillo Jr EA, Habicht JP. Epidemiologic evidence for a potentiating effect of malnutrition on child mortality. Am J Public Health. 1993 Aug; 83(8):1130-3.

6. Garrett JL, Ruel MT. Are determinants of rural and urban food security and nutritional status different? some insights from Mozambique. Elsevier Science Ltd. International Food Policy Research Institute, Washington, DC, USA. 2000.

7. Berry AA, Katras M, Sano Y, Lee J, Bauer JW. Job volatility of rural, low-income mothers: a mixed methods approach. J Fam Econ Iss. 2008 Feb; 29(1):5-22.

8. Gregory PJ, Ingram JS, Brklacich M. Climate change and food security. Philos Trans R Soc Lond B Biol Sci. 2005 Nov; 360(1463):2139-48.

9. Francis C, Lieblein G, Gliessman S, Breland TA, Creamer N, Harwood R, et al. Agroecology: the ecology of food systems. J Sustain Agr. 2003; 22(3): 99-118.

10. Gliessman SR. Agroecology: The ecology of sustainable food systems. 2nd edition. Boca Raton, FL, USA: CRC Press, Taylor \& Francis Group; 2007.

11. Frank DJ. Science, Nature, and the Globalization of the Environment, 1870-1990. Soc Forces. 1997; 76(2):409-35.

12. Philippine Standard Geographic Code (PSGC). Philippines Statistics Authority 2016 [Internet]. [cited 2018 Jul]. Available from: http://nap. psa.gov.ph/activestats/psgc/articles/con_urbanrural.asp.

13. Facts and Figures. 8th National Nutrition Survey [Internet]. Food and Nutrition Research Institute. 2013 [cited 2018 Jul]. Available from: http://enutrition.fnri.dost.gov.ph/site/assets/uploads/ Overview_8thNNS_050416.pdf 
14. Social Weather Survey Result 2015. First to Fourth Quarter 2015 Hunger Result in the Philippines [Internet]. [cited 2018 Jul]. Available from: http://swsresult2015firsttofourthquarter//sws.org.ph.

15. Updating of the Nutritional Status of the Filipino Population: Local Level Food, Health and Nutrition Survey. Food and Nutrition Research Institute; Occidental Mindoro: Philippines. Provincial Nutrition Action Office of the Province of Occidental Mindoro. 2016.

16. Philippine Plan of Action for Nutrition 2017-2022: A call to urgent action for Filipinos and its leadership [Internet]. National Nutrition Council; Taguig City: Philippines. 2017 [cited 2018 Jul]. Available from: http://www.nnc.gov.ph>technical-papers>document.

17. Radimer KL, Olson CM, Greene JC, Campbell CC, Habicht JP. Understanding hunger and developing indicators to assess it in women and children. J Nutr Educ.1992 Jan-Feb; 24(1):36S-44S.

18. Sharkey JR, Johnson CM, Dean WR. Relationship of household food insecurity to health-related quality of life (HRQOL) in a large sample of rural and urban women. Women Health. 2011 Jul; 51(5), 442-60. doi: 10.1080/03630242.2011.584367.

19. Mathews L, Morris MN, Schneider J, Goto K. The relationship between food security and poor health among female WIC participants. J Hunger Environ Nutr. 2010; 5(1):85-99.

20. Seefeldt KS, Castelli T. Low-Income Women's Experiences with Food Programs, Food Spending, and Food-Related Hardships: Evidence from Qualitative Data. Washington, D.C: Economic Research Service: Food and Nutrition Assistance Program; 2009.

21. Ramirez MARM, Viajar RV, Azana GP. Construct Validity of an Adapted Radimer/CornellMeasure of FoodInsecurityin thePhilippines. BMJ Open. 2015; 5(suppl 1):bmjopen-2015-forum2015abstracts.76. doi: 10.1136/bmjopen-2015-forum2015abstracts.76.

22. Hoddinott JF, Yohannes Y. Dietary diversity as a food security indicator [Internet]. International Food Policy Research Institute, Washington DC. 2002 [cited 2018 Jul]. Available from: http://orcid.org/00000001-7932-1816.

23. Hatloy A, Hallund J, Diarra MM, Oshaug A. Food variety, socioeconomic status and nutritional status in urban and rural areas in Koutiala (Mali). Public Health Nutr. 2000 Mar; 3(1):57-65.

24. Guidelines for measuring household and individual dietary diversity [Internet]. Food Agriculture Office: Rome. 2010 [cited 2018 Jul]. Available from: http://www.fao.org/3/a-1983e.pdf.

25. Savy M, Martin-Prevel Y, Traissac P, Emyard-Duvernay S, Delpeuch F. Dietary diversity scores and nutritional status of women change during the seasonal food shortage in rural Burkina Faso. J Nutr. 2006 Oct; 136(10):2625-32.

26. Steyn NP, Nel JH, Nantel G, Kennedy G, Labadarios D. Food variety and dietary diversity scores in children: are they good indicators of dietary adequacy? Public Health Nutr. 2006 Aug; 9(5):644- 50.

27. Arimond M, Torheim LE, Wiesman D, Joseph M, Carriquiry A. Dietary diversity as a measure of the micronutrient adequacy women's diets: results from rural Bangladesh site [Internet]. Washington (DC): Food and Nutrition Technical Assistance II Project, Academy for Educational Development. 2009 [cited 2018 Jul]. Available from: http://www.fantaproject.org/downloads/pdfs/WDDP_Philippines _Dec09.pdf).

28. Kennnedy GL, Pedro MR, Seghieri C, Nantel G, Brouwer I. Dietary diversity score is a useful indicator of micronutrient intake in nonbreast-feeding Filipino Children. J Nutr. 2007 Feb; 137(2):472-7.
29. Agriculture, value added (\% of GDP). World Bank National data [Internet] 2016 [cited 2018 Jul]. Available from: http://data.worldbank. org/indicator/NV.AGR.TOTL.ZS.

30. Province of Occidental Mindoro [Internet]. PSGC Interactive. Quezon City, Philippines: Philippine Statistics Authority. [cited 2018 Jan]. Available from: http://rssomimaropa.psa.gov.ph/.

31. Cohen MJ, Garrett JL. The food price crisis and urban food insecurity. International Institute for Environment and Development (IIED). London; 2009.

32. United Nations 2008 World urbanization prospects: the 2007 revision, CD-ROM edition New York, NY: United Nations Department of Economic and Social Affairs, Population Division.

33. Employment rate in January 2016 is estimated at 94.2 Percent [Internet]. Philippines Statistics Authority 2016. [cited 2018 Aug]. Available from: https://psa.gov.ph/content/employment-rate-january2016-estimated-942-percent.

34. Highlights on household population, number of households, and average household size of the Philippines (2015 Census of Population) [Internet]. Philippines Statistics Authority. 2016 [cited 2018 Jul]. Available from: http://psa.gov.ph/content/highlights-householdpopulation-number-households-and-average-household-sizephilippines.

35. Chakona G, Shackleton CM. Household Food Insecurity along an Agro-Ecological Gradient Influences Children's Nutritional Status in South Africa. Front Nutr. 2017; 4:72. doi:10.3389/fnut.2017.00072.

36. Shisana O, Labadarios D, Rehle T, Simbayi L, Zuma K, Dhansay A, et al. South African National Health and Nutrition Examination Survey (SANHANES-1). Cape Town: HSRC Press; 2013.

37. Liu J, Shively G, Binkley J. Dietary Diversity in Urban and Rural China: An Endogenous Variety Approach Department of Agricultural Economics [Internet]. Purdue University. 2013 [cited 2018 Jul]. Available from: https://ageconsearch.umn.edu/bitstream/149624/2/ joined_document_4.pdf.

38. Oh SY, Hong MJ. Food insecurity is associated with dietary intake and body size of Korean children from low-income families in urban areas. Eur J Clin Nutr. 2003 Nov; 57:1598-1604.

39. Bouis HE, Welch RM. Biofortification- a sustainable agricultural strategy for reducing micronutrient malnutrition in the Global South. Crop Sci. 2010 Mar-Apr. 50:S20-S32.

40. Freebairn DK. Did the Green Revolution concentrate incomes? A quantitative study of research reports. World Dev. 1995; 23:265-79.

41. Graham RD, Welch RM, Saunders DA, Ortiz- Monasterio I, Bouis $\mathrm{HE}$, Bonierbale M, et al. Nutritious subsistence food systems. Adv Agron. 2007; 92:1-74.

42. Ruel M, Graham J, Murphy S, et al. Validating simple indicators of dietary diversity and animal source food intake that accurately reflect nutrient adequacy in developing countries. Report submitted to GL-CRSP; 2004.

43. Waswa LM, Jordan I, Hermann J, et al. Household food security and dietary diversity in different agro- ecological zones in Western Kenya [Internet]. Biodiversity International. 2017 [cited 2019 Mar 23]. Available from: www.biodiversityinternational.org. 